\title{
Lipoabdominoplasty: Revisiting the Superior Pull-Down Abdominal Flap and New Approaches
}

\author{
Carlos Oscar Uebel
}

Received: 15 October 2008/Accepted: 19 January 2009/Published online: 19 March 2009

(C) The Author(s) 2009. This article is published with open access at Springerlink.com

\begin{abstract}
Abdominoplasty is a very common procedure, especially for patients with abdominal laxness, striaes, and muscle rectus diastases. With the advent of liposuction 28 years ago, we can improve body contouring by treating lipodystrophies in the epigastric, flank, trochanteric, and buttocks areas. The procedure combining abdominoplasty and liposuction is called lipoabdominoplasty. Many new techniques have been proposed since these procedures were introduced; we now revisit the superior pull-down abdominal flap technique with several new modifications and improvements.
\end{abstract}

Keywords Lipoabdominoplasty ·

Minilipoabdominoplasty · Pull-down abdominal flap ·

Abdominoplasty $\cdot$ Body contouring

Liposuction came on the scene 28 years ago [1]. Since lipoabdominoplasty was first described by Callia [2] and Pitanguy [3], many refinements to the procedure have been published [4-14]. In 1975, Sinder [15] described the superior epigastric incision approach to estimate a safe inferior abdominal flap excision. Planas [16] published a similar procedure, and Serson Neto [17] and Pontes [18] described the geometrical inferior flap block resection. Stemming from those techniques, we have introduced some

C. O. Uebel

Division of Plastic Surgery, Pontificia Universidade Catolica, Rio Grande Sul - PUCRS, Rio Grande Sul, Brazil

C. O. Uebel $(\bowtie)$

Vitor Hugo St. 78, 90630-070 Porto Alegre, Brazil

e-mail: carlos@uebel.com.br important approaches and details to ensure superior flap safety and to improve postoperative results; they are summarized here.

With the patient in a sitting position, we estimate the amount of skin to be resected and outline the extension of the inferior suprapubic incision by the inguinal groove extremities. Epidural anesthesia via catheter is usually used, with bandage compression on the legs to prevent thrombovenous embolism. The first surgical step consists of releasing the superior abdomen wall with an assisted mechanical cannula liposuction procedure, originally described by Saldanha [19] and Avelar [20]. The incision starts in the supraumbilical area and goes to the xiphoid appendix through a narrow tunnel. The patient is placed in a Fowler position, and the superior flap is pulled down to assess whether it will reach the suprapubic line. This maneuver is important to ensure an accurate estimate of the amount of skin needed to be resected without stretching. We then trim the umbilical stack and a block resection of the entire infra-abdominal flap is done. Demarcation of the new umbilicus orifice is done and adhesions stitches, as described by Baroudi [21] and Pollock [22], are placed. Intradermic sutures with longterm absorbable sutures and a compression garment finalize the surgery.

\section{Materials and Methods}

This surgery is indicated in patients with abdominal laxness, extensive striaes, rectus muscle diastases, and localized lipodystrophy, a very common pathology after pregnancy and also in postbariatric surgical patients (Fig. 1). 
Fig. 1 A 42-year-old patient with abdominal laxness, striaes, and rectus muscle diastasis

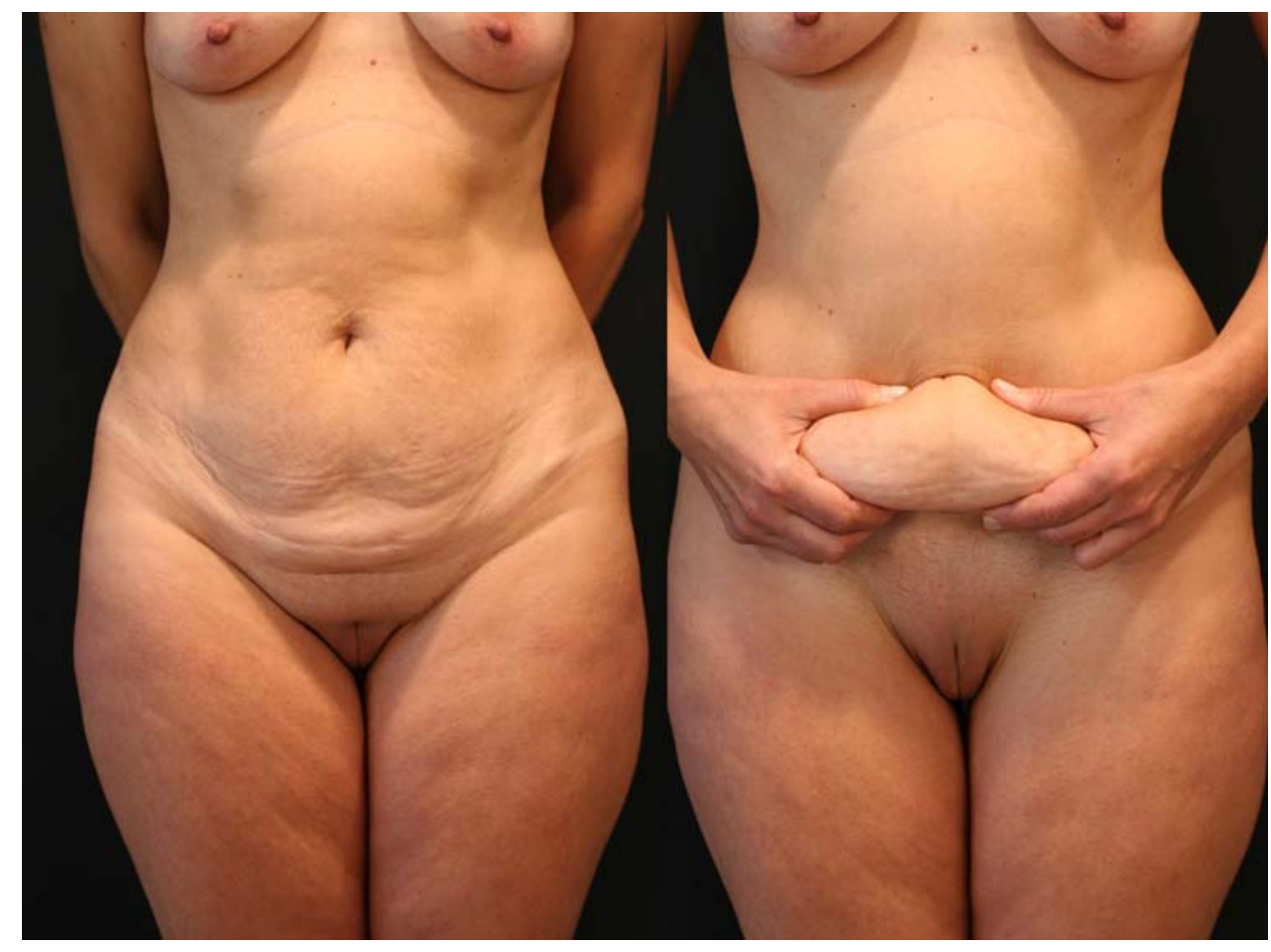

Fig. 2 With the patient in a sitting position, we identify the inguinal groove extremities and the inferior suprapubic incision is outlined
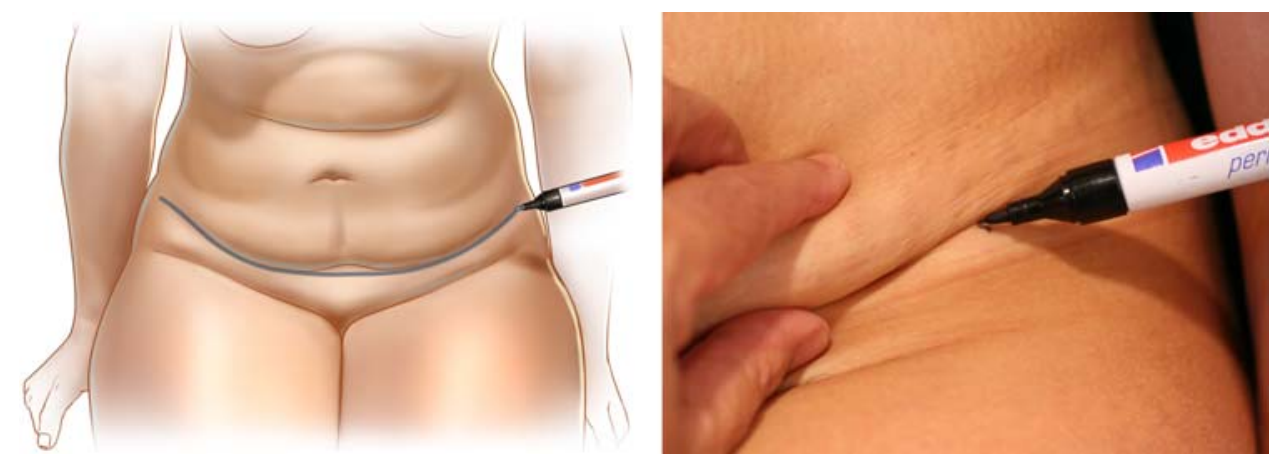

Fig. 3 With the patient standing, we outline the supraumbilicus incision connecting both extremities and we outline the areas to be loosened and undermined

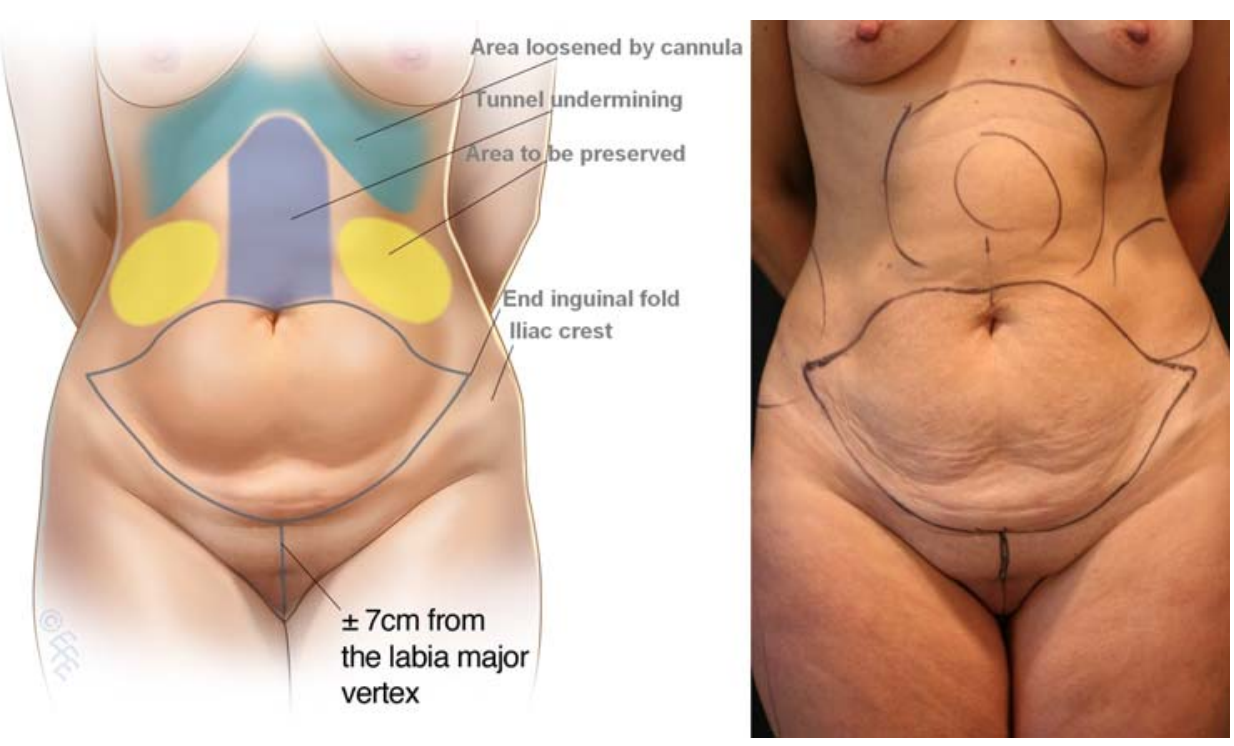


Fig. 4 Epidural anesthesia with catheter for continuous analgesic infusion and leg bandages to prevent thrombovenous embolism
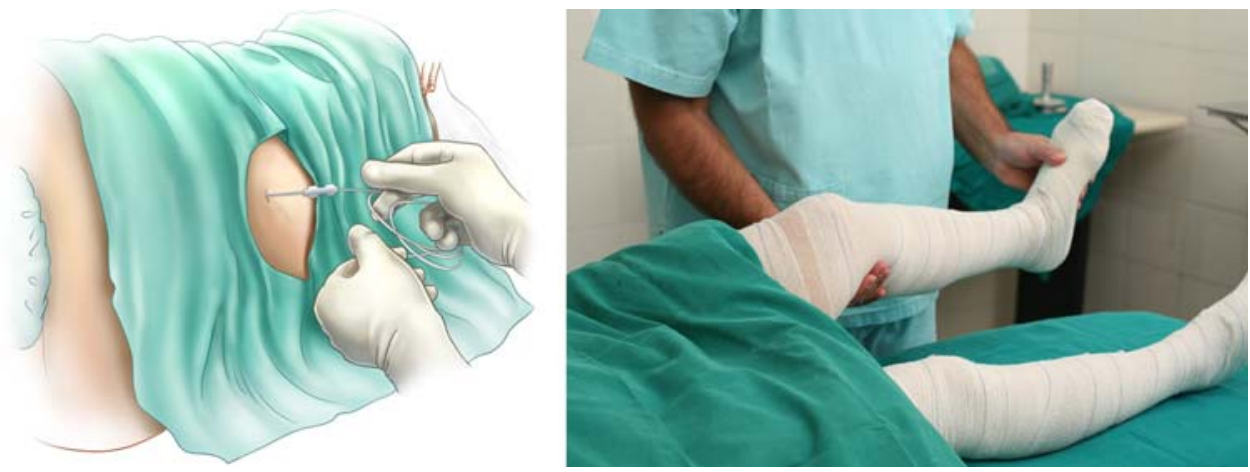

Fig. 5 Supra-condrocostal area to be loosened by angular cannula and flank lateral area to be preserved

Fig. 6 Supraumbilical incision is done first and a tunnel is undermined to the xiphoid process, preserving the lateral neurovascular bundles
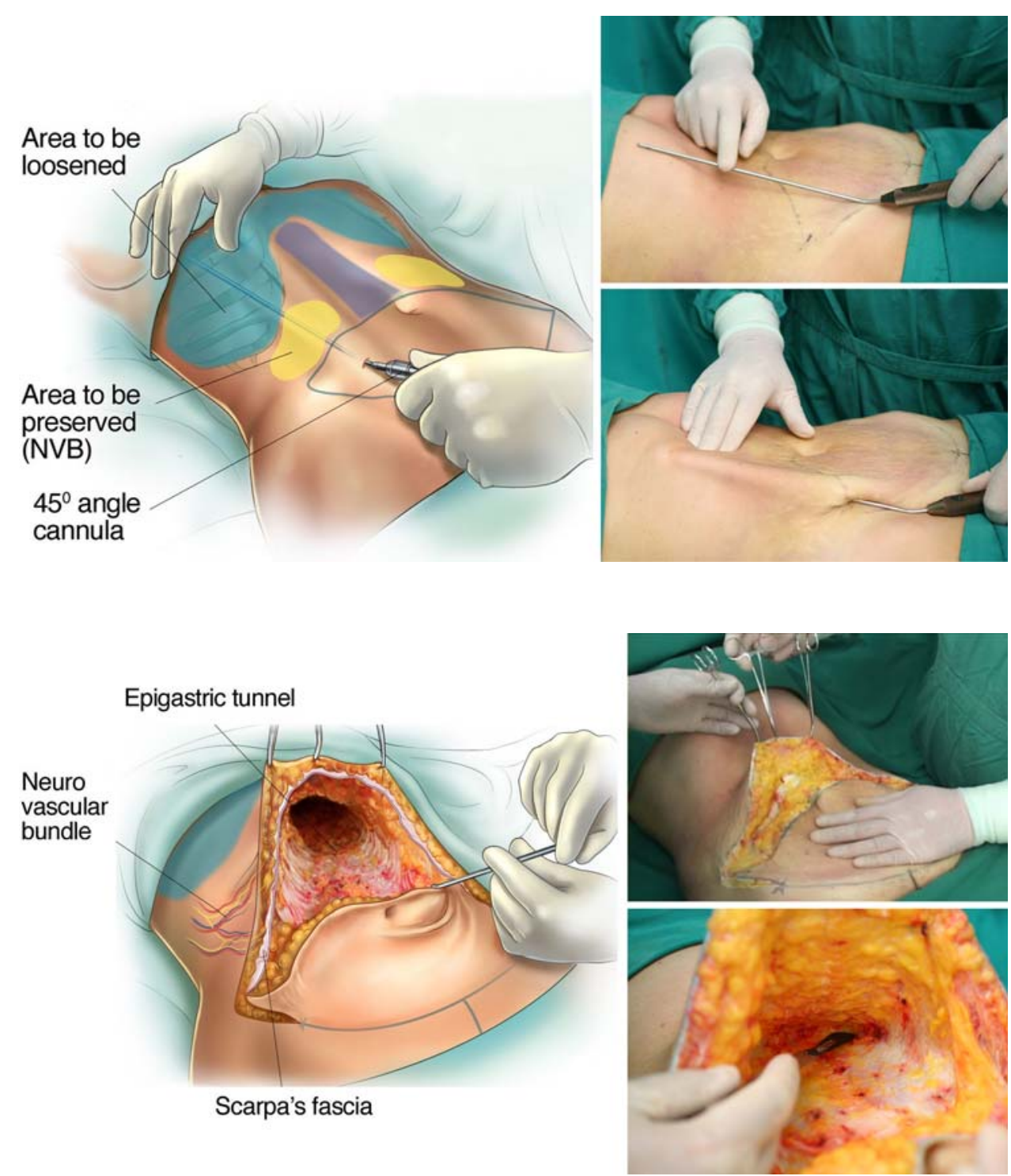

\section{Preoperative Demarcation}

With the patient in a sitting position, we estimate the amount of skin to be resected. We identify the lateral inguinal folds (Fig. 2) and a low abdominal curved line is delineated approximately $8 \mathrm{~cm}$ from the labia major vertex. With the patient standing, a line drawn from the superior umbilical is connected to both extremities and the areas to undergo liposuction are outlined (Fig. 3). 


\section{Anesthesia}

An epidural catheter is inserted in the 11-12 spinal space and connected to a continuous infusion pump. A 15-ml solution of $7.5 \mathrm{mg} / \mathrm{ml}$ ropivacaine $\mathrm{HCl}$ (Naropin) and $30 \mathrm{mg}$ sufentanil citrate is infused into the epidural space and an analgesic solution is prepared for postoperative administration via the infusion pump (100 mg sufentanil citrate and saline solution $0.9 \%, 100 \mathrm{ml}$ at $5 \mathrm{ml} / \mathrm{h}$ ) [23]. Elastic bandages are applied to the legs to prevent thrombovenous embolism (Fig. 4).

Tumescent Infiltration and Assisted Liposuction

All areas to be lipoaspirated and undermined are infiltrated with a saline solution containing epinephrine at 1:500,000 concentration to avoid excessive bleeding. The patient is put in a prone position and the flank and trochanteric areas are manually lipoaspirated with a 3-mm cannula. The patient is then rotated to the supine position and extended liposuction is done to the entire abdomen and epigastric areas. It is important to reach the inframammary region and the xiphoid appendix, extending to the condrocostal border, to fully loosen this area. For this maneuver we use an angular cannula, described by Reggazzo (personal communication), to prevent internal perforations. The only region to be avoided is the lateral superior flank in order to avoid damaging the neurovascular bundles that give arterial, venous, and neural support to the flap (Fig. 5).

Supraumbilical Incision and Epigastric Tunnel Undermining

A supraumbilical incision is first done and an epigastric tunnel is undermined to the xiphoid appendix (Fig. 6). It is important to preserve the lateral superior flank area and to avoid damage to the neurovascular bundles that support the entire flap. We have already described this [24, 25] and proposed the miniabdominoplasty technique (Fig. 7), stressing the importance of preserving the lateral columns when undermining the long xipho-pubis tunnel and total umbilical stack section.

\section{Pull-Down Flap Approach}

The patient is put in the Fowler position and the flap is pulled down to try to reach the inferior suprapubic line

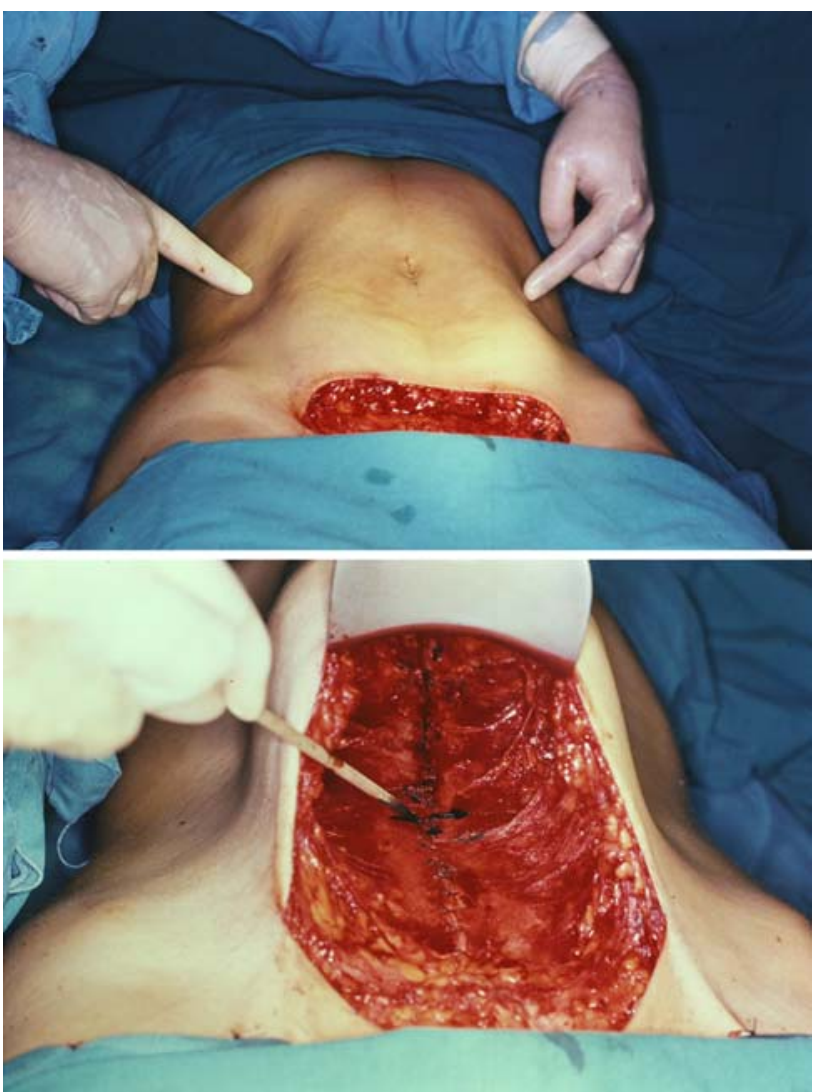

Fig. 7 Lipominiabdominoplasty proposed by the author in 1987, with total amputation of the umbilicus stack and undermining of a long xipho-pubis tunnel, preserving the lateral neurovascular bundles

delineated previously and to estimate whether the inferior flap resection can be done en bloc without problems (Fig. 8). This maneuver is critical to determine whether the defect can be closed without stretching. The inferior suprapubic line can then be moved up or down depending on the laxness and elasticity of the skin and patient biotype. Normally, it is approximately $7-8 \mathrm{~cm}$ from the labia major vertex.

\section{Umbilical Stack Circumcision and Inferior Flap Block Resection}

After confirming the safety of the pull-down approach, the patient is again placed in the horizontal position and the umbilical stack is trimmed to an elliptical shape. The suprapubic incision is done superficially to avoid damaging the lymphatic vessels and the cutaneous muscle nerves that give the lateral thighs sensibility. We preserve a border of 4-5 cm of the aponeurosis superficialis-scarpa fascia. Then the entire flap is raised en bloc from the abdomen wall (Fig. 9). 
Fig. 8 The patient is in the Fowler position and the superior flap is pulled down to try to reach the inferior suprapubic outlined incision. This is a safety measure to prevent stretching and undesirable vascular complications

Fig. 9 The inferior flap is raised en bloc, preserving the umbilicus stack and an inferior border of 4-5 cm of scarpa fascia to protect the lymphatic vessels and the cutaneus muscle nerves
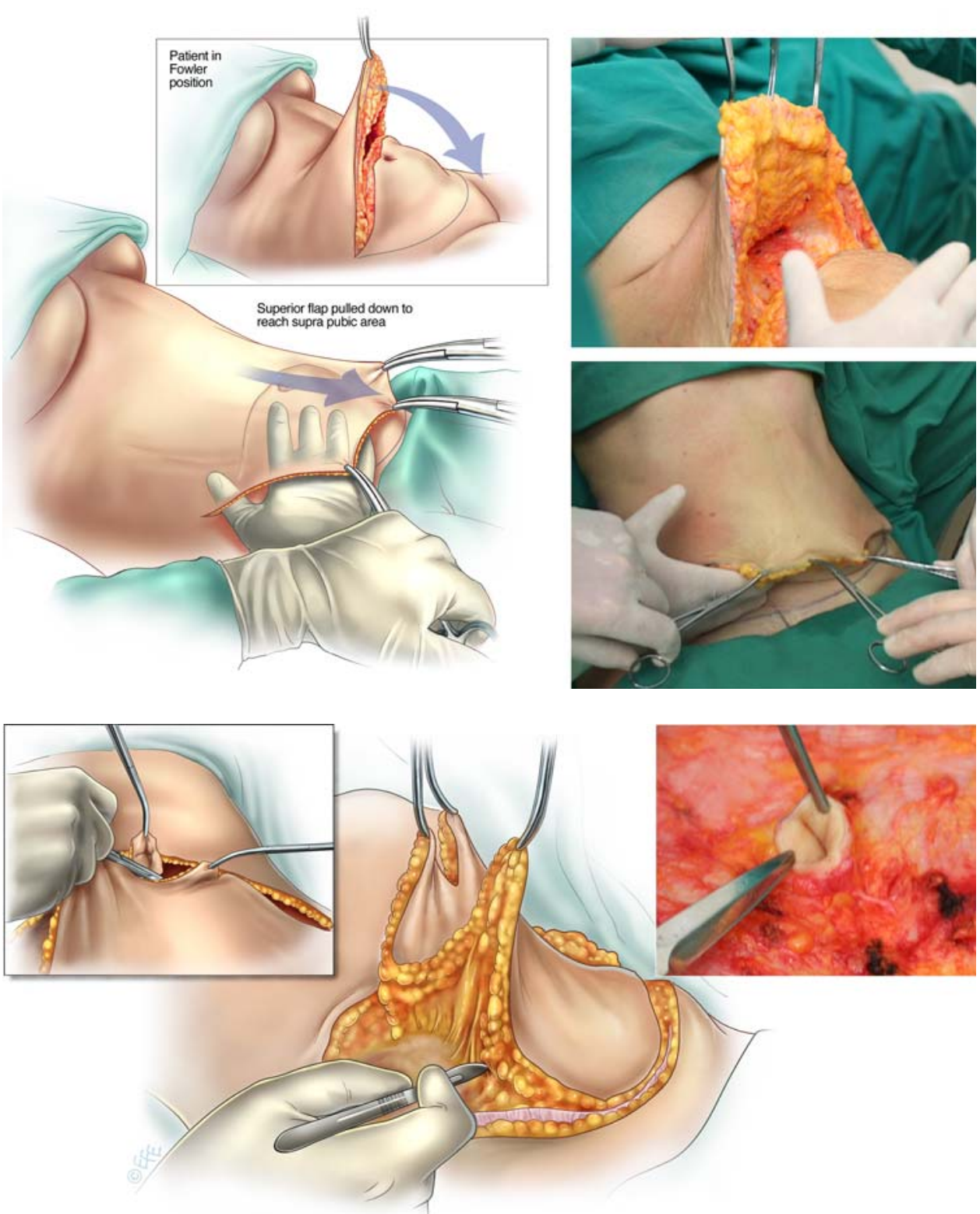

Fat Trimming

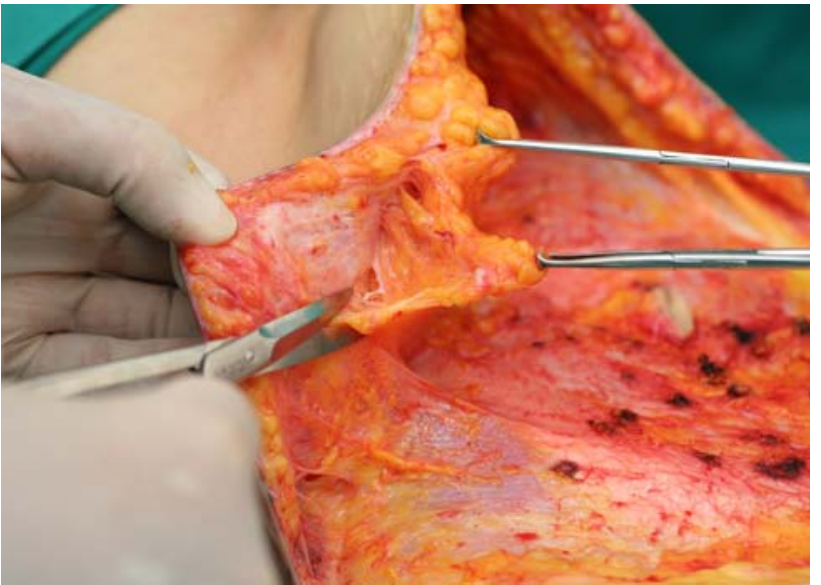

Fig. 10 The excess abdominal wall fat is trimmed away, preserving the scarpa fascia and the neurovascular bundles
The excess fat from the upper flap is trimmed, preserving the scarpa fascia and the superior lateral pedicle of the nerves, veins, and arteries-the branches that supply the entire abdomen flap and which cannot be undermined. The scarpa fascia protects those branches laterally (Fig. 10).

\section{Rectus Muscle Aponeurotic Plication}

The rectus muscle diastasis is identified and two lines are drawn from the xiphoid appendix to the suprapubic area. A 3-0 nylon nonabsorbable suture (PDS) is used; sutures start from the epigastric area down to and including the umbilicus stack in a medium-to-firm fixation. We then have a tunnel approximately $6 \mathrm{~cm}$ wide 
Fig.11 Plication of the muscle aponeurosis diastases, fixing the umbilicus stack, and preserving the lateral neurovascular bundles
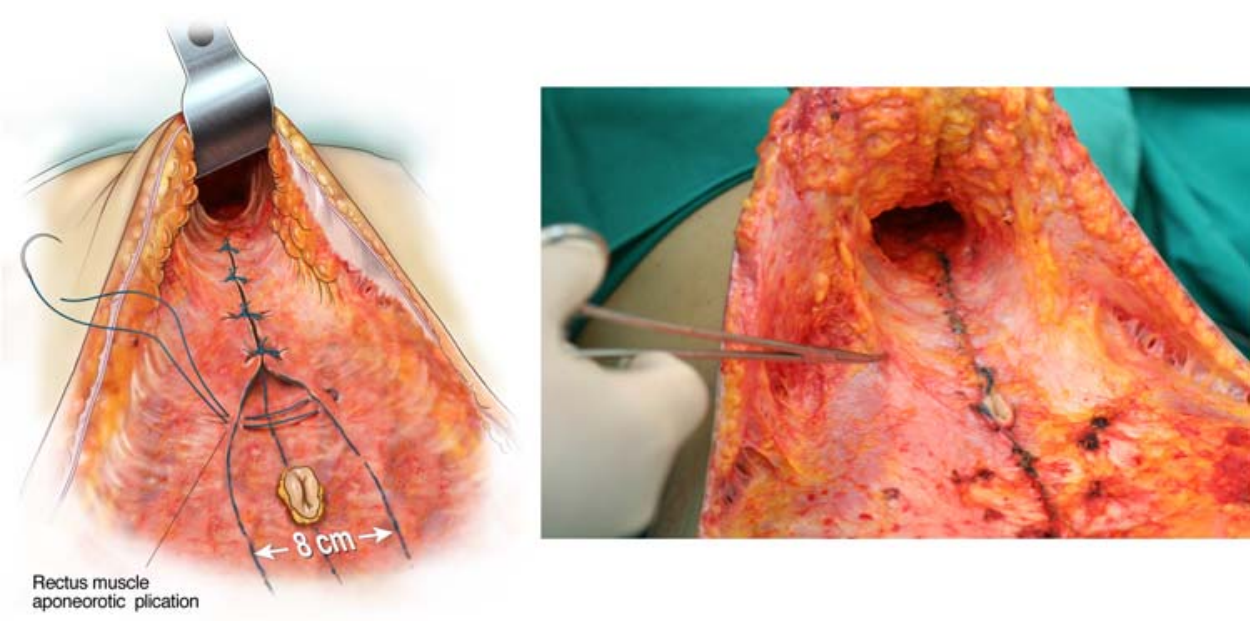

Fig. 12 With the patient in a semi-Fowler position $\left(45^{\circ}\right)$ we identify the umbilicus stack and bring it upward $2 \mathrm{~cm}$ to release the suprapubic stretching
Fig. 13 A criss-cross incision is done and the umbilicus stack is exteriorized and fixed with four stitches deep into the aponeurotic level
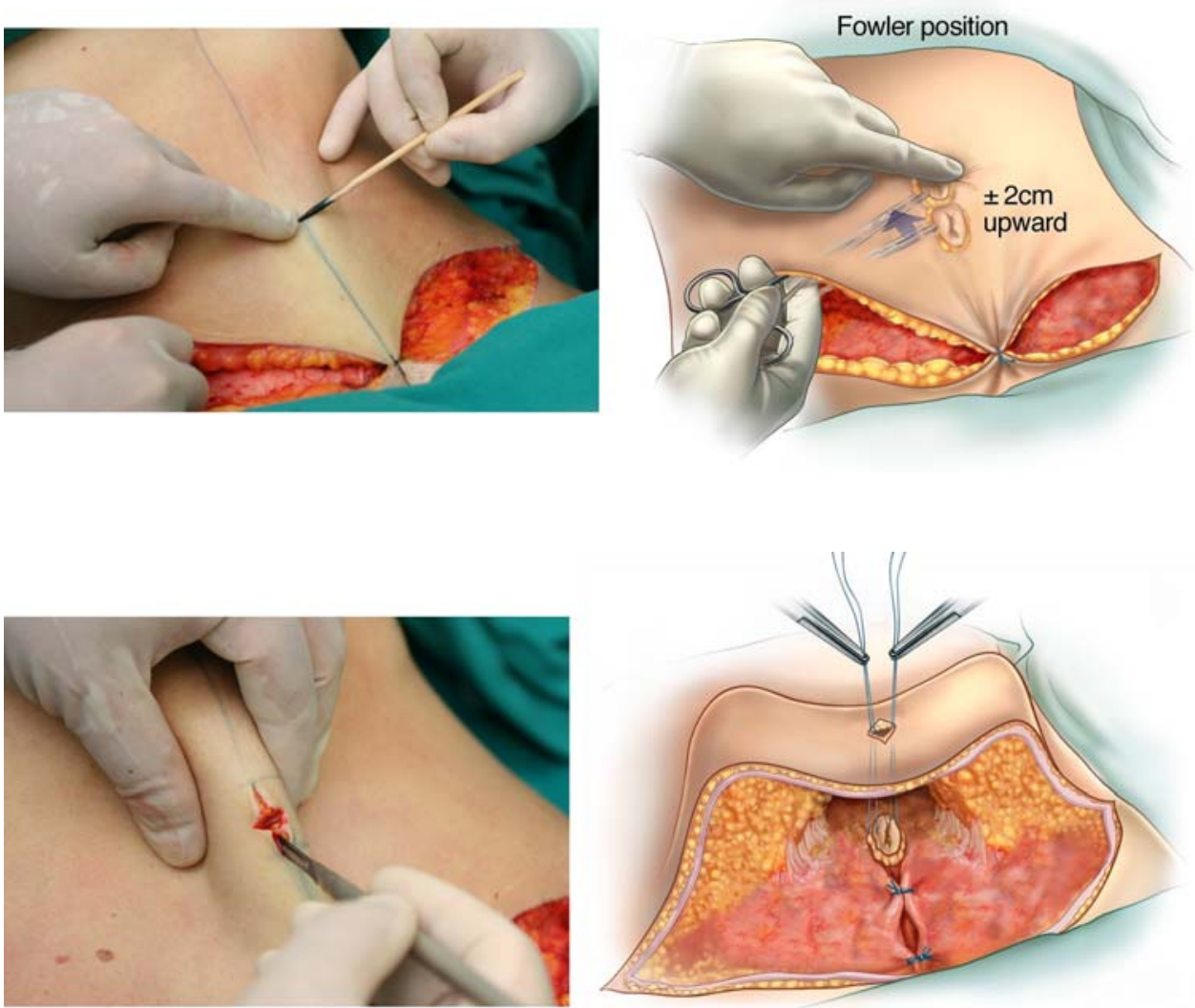

and a waist improvement of approximately $8 \mathrm{~cm}$ (Fig. 11).

\section{Exteriorization of the Umbilicus Stack}

The patient is put in a semi-Fowler position $\left(45^{\circ}\right)$ and the flap is extended to the pubis area. A 2-0 nylon stitch is placed to support the flap, and, using Allis forceps, the umbilicus stack is grasped and projected to the abdomen wall. We identify it with blue methylene, marking 1.5$2 \mathrm{~cm}$ above its new position (Fig. 12). This procedure is very important to avoid stretching or vascular damage to the suprapubic area. With a No. 11 blade, we make a crossshaped incision approximately $2 \mathrm{~cm}$ long and $1 \mathrm{~cm}$ wide. We trim the surrounding fat and four repairing stitches are placed to fix the umbilicus stack deep into the muscle aponeurotic plane (Fig. 13). 
Fig. 14 Several adhesion stitches are made to fix the subcutaneous "dead space," and the inferior scarpa fascia is sutured into the flap to protect the lymphatic vessels and musculocutaneous nerves
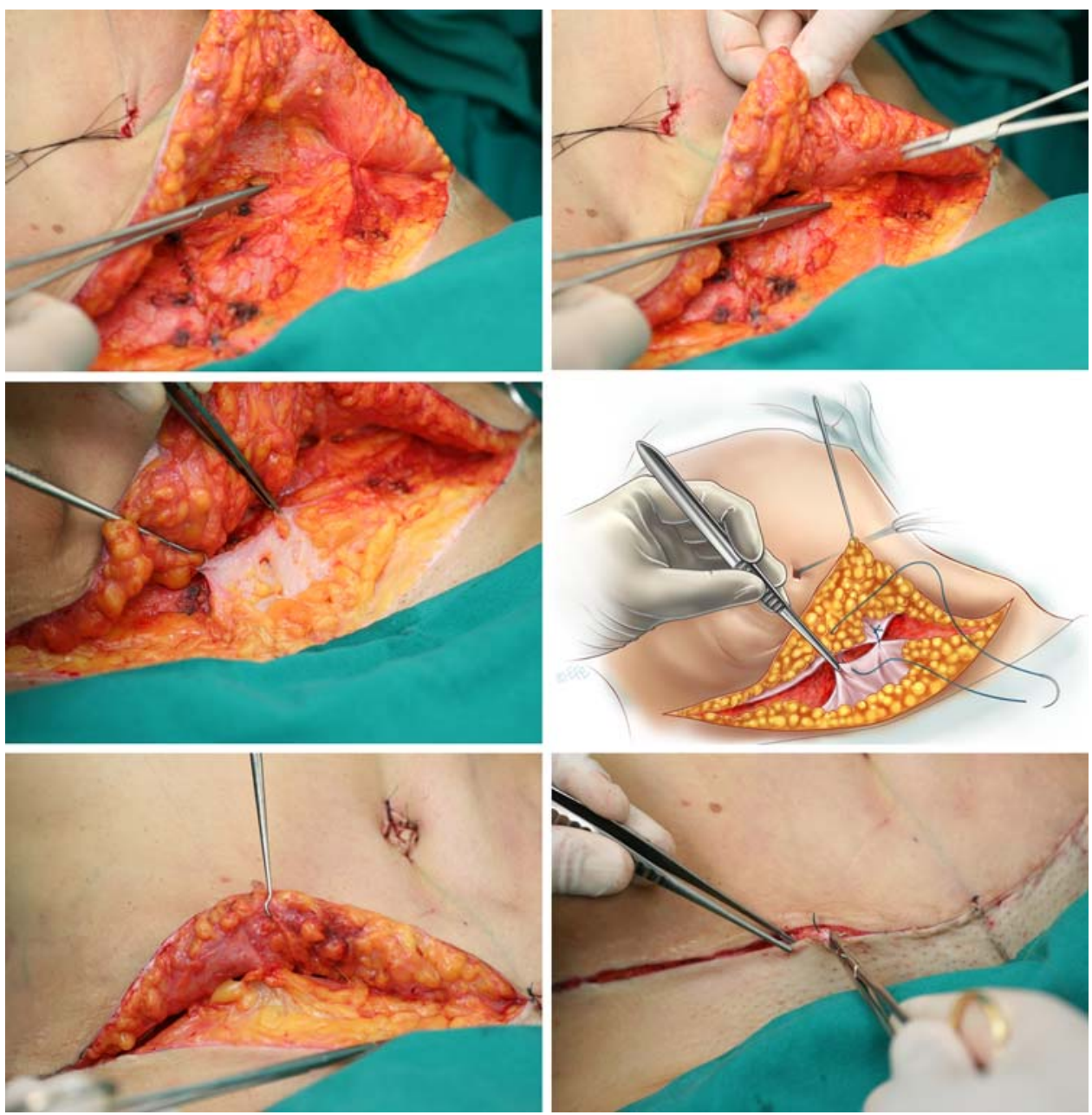

\section{Subcutaneous Adhesion Stitches and Closing Sutures}

Approximately 10-12 nonabsorbable 4-0 stitches are placed in the subcutaneous level, fixing the scarpa fascia to the muscle aponeurotic tissue. This procedure was described by Baroudi [21]; a posterior approach was described by Pollok [22] to diminish the "death space" and to avoid flap sliding, preventing hematomas and seromas postoperatively. The inferior scarpa fascia border is sutured together with the subcutaneous flap to protect the lymphatic vessels and musculocutaneous nerves. Even with these stitches, we maintain a suction drain for $12 \mathrm{~h}$. Subcutaneous and intradermic sutures are made with monocryl 4-0, and micropore sterile strips are attached to the new scar (Fig. 14).

\section{Postoperative Remarks}

Support undergarments are placed on the patient to reinforce and maintain pressure on the abdomen wall. The patient is kept in the hospital overnight; the epidural catheter is kept connected to the pump for $24 \mathrm{~h}$. A solution of sufentanil citrate $(100 \mathrm{mg})$ with saline solution $0.9 \%$ $(100 \mathrm{ml})$ is continuously infused only to prevent pain; no other analgesic drugs are administered. The patient can and should move her legs beginning immediately after the surgery this is important to prevent venous thromboembolism. Intensive care respiratory procedures are observed and leg massages given. The next day the epidural catheter is removed and the patient may start to walk slowly in a hunched position to avoid stretching the abdomen. The patient can be released if vital signs are normal (Figs. 15, 16, 17).

\section{Clinical Dates and Results}

In the last 8 years we have performed this technique on 326 patients, all with these related improvements. Table 1 gives our data regarding complications. In two patients suprapubic epidermolyses occurred. Both patients were heavy 
Fig. 15 The same patient 3 months after surgery. She had a breast augmentation as well
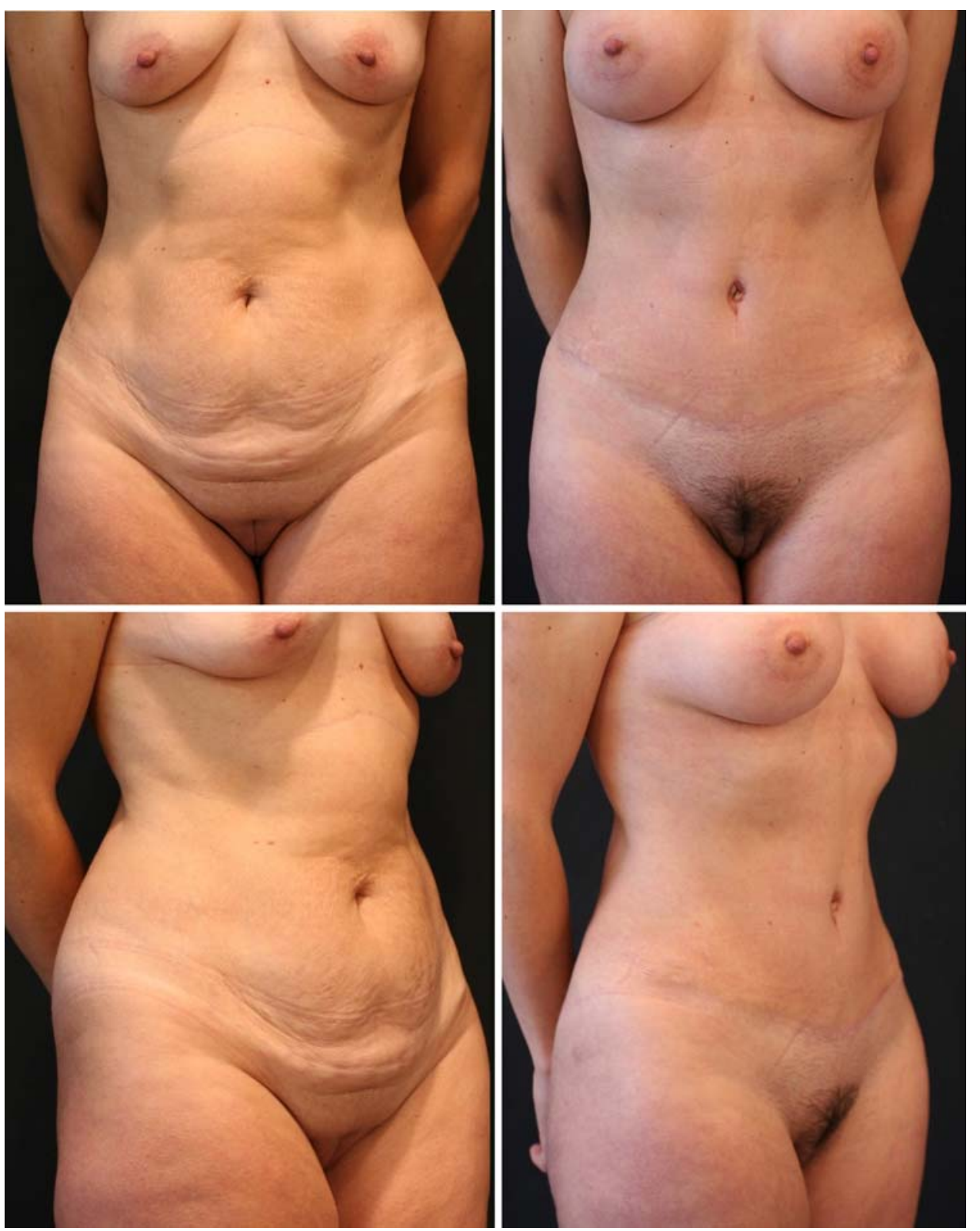

smokers and although they stopped smoking 15 days before surgery, we observed epidermolyses in the suprapubic area which diminished with administration of buflomedil cloridrate $300 \mathrm{mg}$ twice daily for 7 days starting 2 days before the surgery. In three obese patients seromas appeared 5-6 days after surgery. In those patients we had performed an intensive lipectomy of the flap and although we had used adhesion subcutaneous stitches, seroma resulted. Hypertrophic scars occurred in eight patients, three with white skin and five with black or multiethnic skin. Scar revision and "dog ear" correction was required in 12 patients.
Heller et al. [26] recently published a retrospective cohort study that evaluated four groups of abdominoplasty patients. Group I received only abdominal liposuction; group II received traditional W-pattern incision line abdominoplasty; group III had modified transverse incision abdominoplasty; and group IV underwent a combined procedure of liposuction and short undermined abdominoplasty. Heller et al. concluded that group IV had fewer complications than the other groups. When we compare these data with our group of lipoabdominoplasty patients, we had similar results with a lower percentage of complications. 

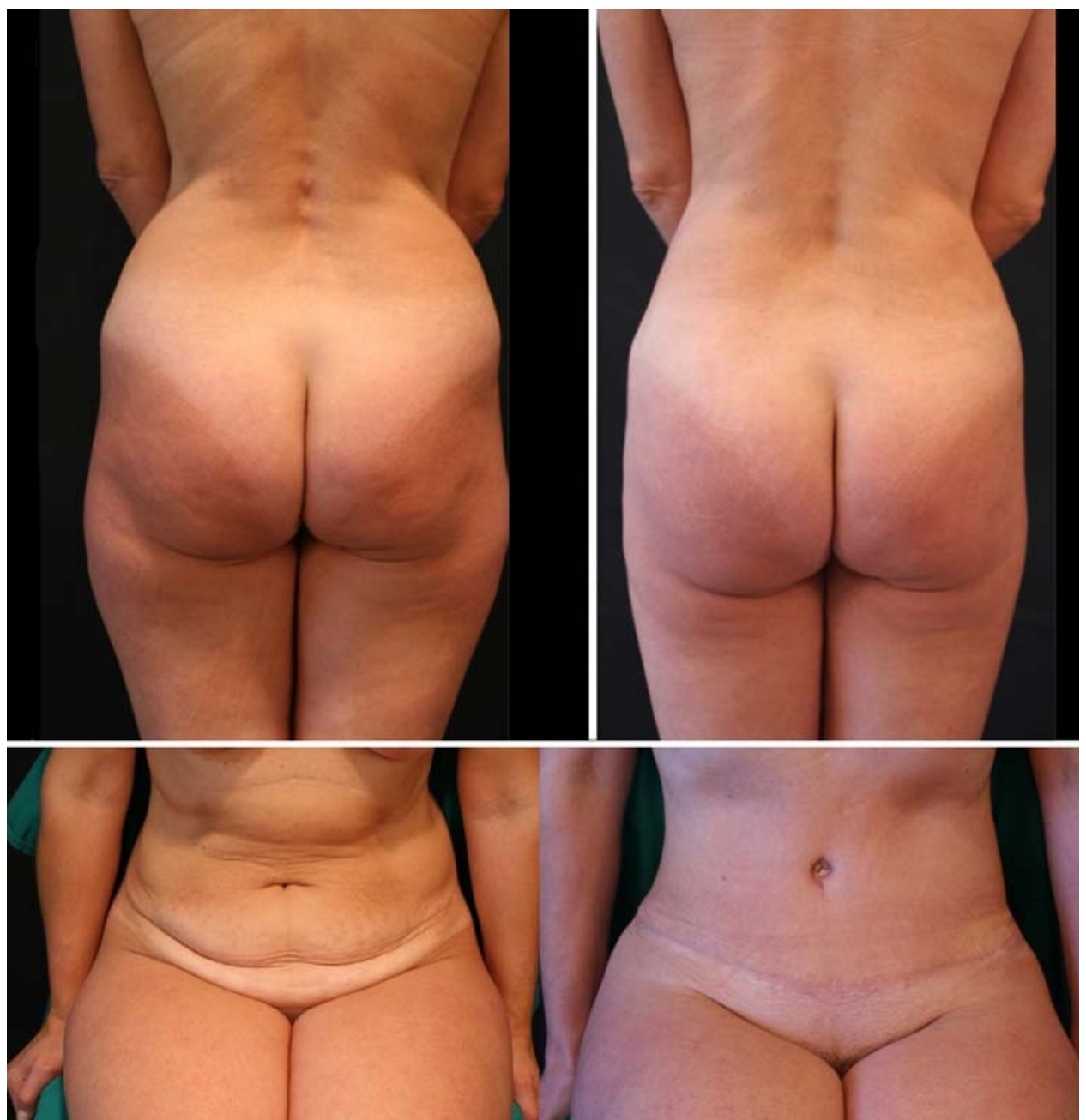

Fig. 16 Back view showing the body contour obtained by liposuction and patient in the preoperative and postoperative sitting position

\section{Conclusion}

We revisited the superior pull-down abdominal flap described by Sinder and introduced some new approaches and techniques to make it easier and safer: the sitting position to delineate the inferior curved incision, epidural catheter anesthesia, supra-condrocostal liposuction to loosen the inframammary area, undermining of the epigastric area only enough to bring down the flap, keeping the scarpa fascia on the lateral abdomen wall to protect the neurovascular pedicles and in the inferior abdomen to protect the lymphatic vessels and musculocutaneous nerves, exteriorization and fixing the umbilicus stack $2 \mathrm{~cm}$ above its projection, adhesion stitches in the subcutaneous level to prevent seromas, requiring early leg movement and walking-all these improvements have been successfully introduced and
Table 1 Complications

\begin{tabular}{lcl}
\hline Complications & No. of patients & $\%$ \\
\hline Suprapubic epidermolyses & 2 & 0.6 \\
Suprapubic necrosis & 0 & 0 \\
Hematomas & 0 & 0 \\
Seromas & 3 & 0.9 \\
Hypertrophic scars & 8 & 2.4 \\
Infections & 2 & 0.6 \\
Dog ear scar revision & 12 & 3.6 \\
Thromboembolisms & 0 & 0 \\
\hline
\end{tabular}

routinely applied in our clinic, reducing the surgical time and diminishing tremendously complications such as seromas, vascular flap necrosis, and venous thromboembolism. 

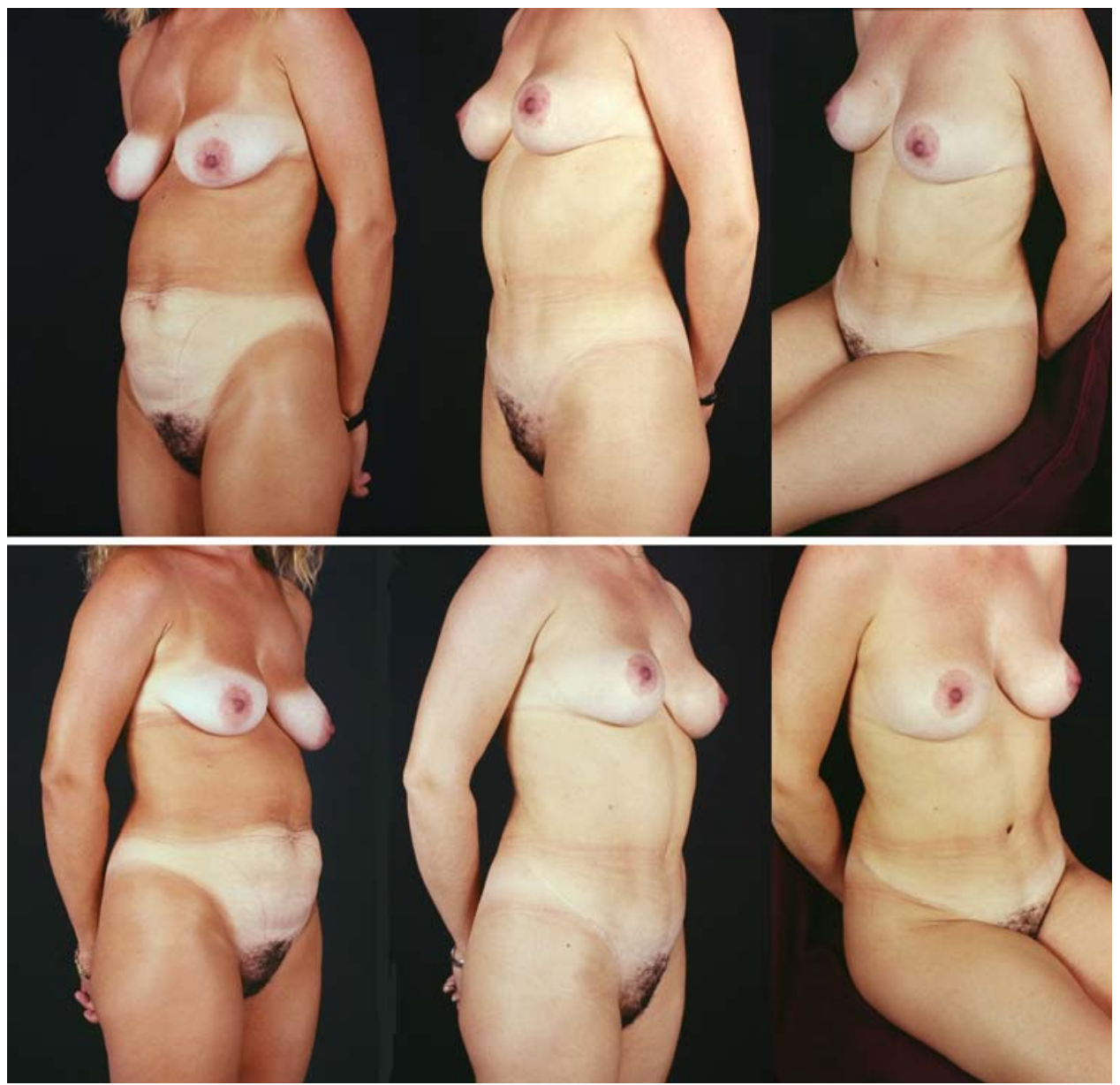

Fig. 17 A 46-year-old patient 2 years after lipoabdominoplasty combined with a mastopexy

Open Access This article is distributed under the terms of the Creative Commons Attribution Noncommercial License which permits any noncommercial use, distribution, and reproduction in any medium, provided the original author(s) and source are credited.

\section{References}

1. Illouz YG (1980) A new technique for the localized lipodistrophies. Es Ver Chir Esth France 6

2. Callia WEP (1965) Contribuição para o estudo da correção cirúrgica do abdômen pêndulo e globoso - técnica original. Tese de Doutoramento apresentada à Faculdade de Medicina da USP, São Paulo, Brazil

3. Pitanguy I (1967) Abdominal lipectomy: an approach to it through an analysis of 300 consecutive cases. Plast Reconstr Surg 40(4):384-391

4. Psillakis J (1978) Abdominoplasty - some ideas to improve results. Aesthetic Plast Surg 2:205-215

5. Baroudi R, Keppke EM, Neto FT (1974) Abdominoplasty. Plast Reconstr Surg 54:161-168

6. Bozola AR, Bozola AC (2003) Addominoplastias. In: Mélega JM (ed) Cirurgia Plástica, Fundamentos e Arte - Cirurgia Estética. MEDSI, São Paulo

7. De Souza Pinto EB, Oliveira RPR (1999) Lipoaspiração superficial. Ed Revinter 3:11-20
8. Baroudi R, Moraes M (1995) A "bicycle-handlebar" type of incision for primary and secondary abdominoplasty. Aesth Plast Surg J 19:307

9. Uebel CO (1994) Cirurgia do abdomen associada à lipoescultura. In: Tourniex AAB (ed) Atualização em Cirurgia Plástica Estética. Robe Editorial, São Paulo, pp 483-489

10. Cardoso de Castro C, Cupello AM, Cintra H (1987) Limited incisions in abdominoplasty. Ann Plast Surg 19:436-447

11. Franco T, Rebello C (1977) Cirurgia Estética. Atheneu, Rio de Janeiro

12. Hakme F (1985) Technical details in the liposuction associated with abdominoplasty. Rev Bras Cir 75:331

13. Abramo de Oliveira E, Valera F, Monte AL, López C (2008) Prevention of seroma in liposuction associated abdominoplasty without active drainage. Rev Soc Bras Cir Plást 23(1):41-47

14. Nahas FX, Ishida J, Gemperli R, Ferreira MC (1998) Abdominal wall closure after seletive aponeurotic incision and undermining. Ann Plast Surg 41:606-613

15. Sinder R (1975) Plastic Surgery of the abdomen - Personal technique. In: Abstracts of the 6th international Congress of plastic and reconstructive surgery. Masson, Paris, p 58

16. Planas J (1978) The "vest over pants" abdominoplasty. Plast Reconstr Surg 61:694-700

17. Serson Neto D, Martins LC (1972) Dermolipectomia abdominal. Abordagem geométrica. Ver Lat Am Cir Plast 16:13

18. Pontes R (2004) Variantes das abdominoplastias em bloco. In: Pontes R (ed) Abdominoplastia: ressecção em bloco e sua 
aplicação em lifting de coxa e torsoplastia. Revinter, Rio de Janeiro, pp 25-54

19. Saldanha OR (2003) Lipoabdominoplasty with selective and safe undermining. Aesthetic Plast Surg 27(4):322-327

20. Avelar JM (2002) Abdominoplasty without panniculus undermining and resection: analysis and 3 years follow up and 97 consecutives. Aesth Surg J 22:16-25

21. Baroudi R, Ferreira CAAP (1998) Seroma: how to avoid it and how to treat it. Aesth Surg J 18:439-441

22. Pollock H, Pollock T (2000) Progressive tension sutures: a technique to reduce local complications in abdominoplasty. Plast Reconstr Surg 105(7):2583-2586
23. Minetto ZF, Perez SCM (2004) Anestesia em ortopedia e traumatologia. In: Manica J (Org) Anestesiologia: princípios e técnicas, 3rd edn. Artmed, Porto Alegre, Cap 57, pp 979-1005

24. Uebel CO (1987) Miniabdominoplasty-a new approach for the body contouring. Presented at the 9th Annual Congress of the International Society of Aesthetic Surgery, New York, October 1987.

25. Uebel CO (2004) Minilipoabdominoplastiy - its evolution. In: Lipoabdominoplasty. Di Livros, pp 73-85

26. Heller JB, Teng E, Knoll BI, Persing J (2008) Outcome analysis of combined lipoabdominoplasty versus conventional abdominoplasty. Plast Reconstr Surg 121(5):1821-1829 